HISPANIA. Revista Española de Historia, 2007, vol. LXVII, núm. 227, septiembre-diciembre, págs. 881-898, ISSN: 0018-2141

\title{
LINHAGEM E IDENTIDADE SOCIAL NA NOBREZA MEDIEVAL PORTUGUESA (SÉCULOS XIII-XIV)
}

\author{
BERNARDO VASCONCELOS E SOUSA \\ Universidade Nova de Lisboa
}

RESUMEN: La emergencia y afirmación de una nueva bistoriografia sobre la nobleza medieval portuguesa, patente, sobre todo, en los últimos años, se manifiesta en una significativa cantidad de estudios en el ámbito de la bistoria social, cultural y de las mentalidades. La riqueza y singularidade de algunas de las fuentes utilizadas, especialmente los nobiliarios elaborados entre fines del siglo XIII y la década de 1340, estuvieron en el origen de esta renovación que, progresivamente, alargó su análisis a diversas tipologías documentales. El modelo propuesto por Duby para analizar la evolución de las estructuras de parentesco, se reflejó en el tratameinto de este tema en Portugal, a través de los trabajos de José Mattoso. Las investigaciones de los últimos años permitieron confrontar perspectivas y revisar interpretaciones. Asi, se ba visto que entre los siglos XIII y $X I V$, a la par de una estructura de parentesco essencialmente "vertical», patente en la misma estructura de los referidos nobiliarios, permaneció un sistema de transmisión hereditaria del patrimonio que contemplaba a todos los herederos por igual, sin exclusión de segundones ni mujeres. Este último hecho contribuyó a la atomización y dispersión del patrimonio nobiliar, impidiendo durante este período la consolidación de grandes potentados señoriales laicos de base regional.

Palabras Clave: Portugal. Edad Media. Nobleza.

ABSTRACT: The emergence and assertiveness of a new historiography of medieval Portuguese nobility, particularly apparent in the last few years, is revealed by a significant number of studies carried out in the areas of social and cultural bistory and the bistory of mentalities. The wealth and singularity of some of the sources used, with particular reference to the books of nobility drawn up from the end of the $13^{\text {th }}$ century to the 1340s, led to this revival which, however, broadened its analysis to include a variety of document typologies. The model proposed by Duby to analyse the evolution of kinship structure was reflected in this theme's treatment in Portugal through the work of José Mattoso. The research undertaken in the last few years has allowed us to confront perspectives and review interpretations. Thus, throughout the $13^{\text {th }}$ and $14^{\text {th }}$ centuries in Portugal, on a par with an essentially "vertical» 
kinship structure, made clear for example in the very structure of the books of nobility, there remained a system of hereditary transmission of patrimony which treated all heirs as equal, with no exclusion of second sons or females. This fact contributed to the atomization and dispersion of nobiliary property, preventing the constitution of any great and enduring regional secular seigniorial potentates during this period.

\section{KeY WORDS: Portugal. Middle Ages. Nobility}

\section{EMERGÊNCIA E AFIRMAÇÃO DE UMA NOVA HISTORIOGRAFIA SOBRE A NO- BREZA MEDIEVAL PORTUGUESA}

$\mathrm{Na}$ produção historiográfica das últimas três décadas sobre a Idade Média portuguesa, uma das áreas temáticas que conheceu um assinalável progresso foi a da nobreza, encarada sob múltiplas e variadas perspectivas. A riqueza das fontes genealógicas medievais produzidas em Portugal —os nobiliários ou livros de linhagens ${ }^{1}$ - e a sua singularidade no panorama da literatura congénere europeia oferecem possibilidades de investigação de grande alcance. Os estudos de José Mattoso, iniciados nos anos sessenta e setenta do século passado, contribuíram de forma decisiva para uma viragem, tanto do ponto de vista conceptual como do ponto de vista metodológico, promovendo a passagem de uma prática estreitamente genealógica (de que existe, em Portugal, uma imensa tradição) para um tratamento de âmbito simultaneamente mais amplo e mais profundo, relativo à história social e à história da cultura e das mentalidades.

Incidindo fundamentalmente sobre os séculos XI a XIII, aquele autor retomou, em novas bases, a velha questão das origens da monarquia portuguesa e da emergência, estabelecimento e consolidação do reino de Portugal como entidade política independente, no extremo ocidental da Península Ibérica. Sublinhando o papel dos infanções portucalenses, esse estrato intermédio da nobreza, Mattoso desenvolveu uma nova tese sobre as razões que conduziram à autonomização política de um novo reino. Perante o vazio deixado pelo desaparecimento da nobreza condal, as famílias de infanções, a partir sensivelmente do último quartel do século XII, apropriaram-se de funções judiciais anteriormente exercidas por grandes senhores ligados à corte e que representavam a autoridade régia. O exercício do poder judicial implicava, em larga medida, o exercício do poder fiscal. Quanto ao poder militar, os infanções, antes incluídos nos exércitos reais e dos grandes senhores, passavam a exercê-lo à escala local sem terem recebido qualquer delegação de uma autoridade pública. Davam-se, assim, decisivos passos para uma progressiva autonomização "política» essen-

1 Livros Velhos de Linhagens, ed. crítica por J. Piel e J. Mattoso, Academia das Ciências, Nova Série dos Portugaliae Monumenta Histórica, Lisboa, 1980 e Livro de Linhagens do Conde D. Pedro, 2 vols., ed. crítica por J. MatToso, Academia das Ciências, Nova Série dos Portugaliae Monumenta Histórica, Lisboa, 1980. 
cialmente centrada na região do Entre Douro e Minho e na qual desempenharam um papel decisivo as referidas famílias dos antigos infanções, assim alcandoradas a uma posição cimeira do ponto de vista social, político e militar.

Mas esta revisão do problema das origens do reino de Portugal não ficou por aqui, antes se alargou a uma reinterpretação geral da Idade Média portuguesa. A inovadora perspectiva sobre o reinado de Afonso Henriques, o primeiro monarca português (1139-1185), o estudo da estrutura do parentesco entre a nobreza e a articulação dos factos da história política com os dados da história da família abriram novos caminhos de investigação e análise ${ }^{2}$. Numa obra que teve um impacto decisivo entre os medievalistas portugueses, Mattoso integrava os contributos da geografia física e humana, da linguística e da antropologia, propondo uma interpretação sobre as origens e a viabilização de Portugal que radicava na complementaridade de duas grandes áreas histórico-culturais: o "país senhorial» (grosso modo o Entre Douro e Minho, no Noroeste de Portugal, com prolongamentos para o interior Norte) e o "país concelhio» (a corresponder sensivelmente ao Centro e, sobretudo, ao Sul de Portugal) ${ }^{3}$. Além disso, colocava no cerne da reinterpretação da história da primeira dinastia portuguesa a tensão entre a afirmação do poder da Coroa e as prerrogativas do poder senhorial, chamando a atenção para diversas conjunturas em que esta oposição se fez sentir de forma aberta ou latente.

Para os séculos XII a XIV, os estudos sobre a nobreza multiplicaram-se em larga medida sob a orientação de Mattoso ${ }^{4}$, mas também por iniciativa de ou-

2 Mattoso, J.: Obras Completas, 5, Ricos-Homens, Infanções e Cavaleiros, Lisboa, Círculo de Leitores, 2001; a edição original, de 1982, tinha como subtítulo A Nobreza Medieval Portuguesa nos Séculos XI e XII. Este autor publicou recentemente uma biografia do primeiro rei de Portugal que constitui a mais completa e sugestiva síntese da sua vida e acção política: D. Afonso Henriques, Lisboa, Círculo de Leitores, 2006.

3 Mattoso, J.: Obras Completas, 2, Identificação de um País. Oposição e 3, Identificaşão de um País. Composição, Lisboa, Círculo de Leitores, 2001. A edição original, de 1985, tinha como subtítulo Ensaio sobre as Origens de Portugal. 1096-1325. Para o estudo da nobreza interessa, sobretudo, o primeiro volume.

4 A título de exemplo, vejam-se KRUS, L.: A Concep̧̧ão Nobiliárquica do Espaço Ibérico (12801380), Lisboa, Fundação Calouste Gulbenkian, JNICT, 1994: VenturA, L.: A Nobreza de Corte de Afonso III, 2 vols., Coimbra, Faculdade de Letras, tese de doutoramento policopiada, 1992: Oliveira, A. R. de: Depois do Espectáculo Trovadoresco. A Estrutura dos Cancioneiros Peninsulares e as Recolhas dos Séculos XIII e XIV, Lisboa, Colibri, 1994; RosA, M. L.: O Morgadio em Portugal, Séculos XIV e XV. Modelos e Práticas de Comportamento Linhagístico, Lisboa, Estampa, 1995; GoMES, R. C.: A Corte dos Reis de Portugal nos Finais da Idade Média, Carnaxide, Difel, 1995; OliveIRA, L. F.: A Casa dos Coutinhos. Linhagem, Espaço e Poder (1360-1452), Cascais, Patrimonia, 1999; PizArro, J. A.: Linhagens Medievais Portuguesas. Genealogias e Estratégias (1279-1325), Porto, Universidade Moderna, 1999 e Sousa, B. V.: Os Pimentéis. Percursos de uma Linhagem da Nobreza Medieval Portuguesa (Séculos XIII-XIV), Lisboa, Imprensa Nacional, Casa da Moeda, 2000. Para um balanço mais completo, veja-se Mattoso, J.: «Perspectivas Actuais sobra a Nobreza Medieval Portuguesa», in Obras Completas, 1, Naquele Tempo. Ensaios de História Medieval, Lisboa, Círculo de Leitores, 2000, pp. 341362 (publicado originalmente na Revista de História das Ideias, 19 (1998), pp.7-37). 
tros investigadores'. Para o século XV a investigação pioneira foi realizada por Humberto Baquero Moreno, com o estudo sobre a conjuntura política em que teve lugar a batalha de Alfarrobeira (1449), considerada um momento crucial para a nobreza quatrocentista portuguesa ${ }^{6}$. Relativamente a personagens ou casas senhoriais do século XV merecem ainda referência os trabalhos de Luís Adão da Fonseca, sobre um membro da família real portuguesa que em 1463 chegou a intitular-se conde de Barcelona e rei de Aragão ${ }^{7}$, de João Silva de Sousa acerca da casa senhorial de Henrique, o Navegador ${ }^{8}$, e de Mafalda Soares da Cunha sobre a importante Casa de Bragança?

Se, numa óptica essencialmente genealógica, é possível dizer que os trabalhos sobre a nobreza perduraram, desde a Idade Média até aos nossos dias, sem grandes nem, muito menos, definitivas rupturas, é claro que o estudo moderno e cientificamente conduzido sobre a nobreza medieval portuguesa não se pode filiar, pelo menos de forma directa, naquele interesse em proceder ao registo dos nomes e dos feitos de sucessivas gerações fidalgas que remonta, em Portugal, no mínimo, às décadas de oitenta ou de noventa do século XIII, quando foi elaborado o mais antigo nobiliário que chegou até nós, o chamado Livro Velho. Mas sem dúvida que o nosso conhecimento acerca da nobreza medieval e as possibilidades de o aprofundarmos são fortemente tributários desses registos dos finais da centúria de duzentos e da década de quarenta do século XIV. Embora os livros de linhagens fossem de há muito conhecidos e estivessem até publicados em diversas versões, a sua edição crítica por Joseph Piel e por José Mattoso, dada à estampa em $1980^{10}$, constituiu um avanço decisivo para a investigação em torno deste tema, permitindo ultrapassar a perspectiva genealógica tradicional e proceder a novas abordagens centradas na história social e das mentalidades. Os estudos do próprio Mattoso, alguns deles anteriores em cerca de vinte anos à sua edição dos nobiliários, abriram a via para essa nova perspectiva sobre a nobreza medieval portuguesa. A riqueza e a qualidade informativa dos livros de linhagens, a utilização sistemática de fontes arquivísticas, principalmente dos fundos monásticos, a decisiva influência de Léopold Génicot e, mais tarde, de Georges Duby, conferiram à investigação e à produção

5 Veja-se o caso de Tavares, M. J. F.: «A Nobreza no Reinado de D. Fernando e a sua Actuação em 1383-1385», Revista de História Económica e Social, 12 (1983), pp. 45-89. Sobre a cojuntura da crise dinástica aberta com a morte de Fernando I, veja-se também o estudo de Mattoso, J.: «A Nobreza e a Revolução de 1383», in Obras Completas, 6, Lisboa, Círculo de Leitores, 2001, pp. 218-232.

6 Moreno, H. B.: A Batalha de Alfarrobeira. Antecedentes e Significado Histórico, 2 vols., Coimbra, Universidade, reimpressão, 1979-1980 (a primeira edição é de 1973).

7 FonseCA, L. A. da: O Condestável D. Pedro de Portugal, Porto, INIC, 1982 (primeira versão de 1975).

8 Sousa, J. S. de: A Casa Senhorial do Infante D. Henrique, Lisboa, Livros Horizonte, 1991.

9 Cunha, M. S. da: Linhagem, Parentesco e Poder. A Casa de Bragança (1384-1483), Lisboa, Fundação da Casa de Bragança, 1990.

10 Cf. supra, nota 1. 
científica de Mattoso um carácter absolutamente pioneiro na forma de encarar a temática da nobreza, em Portugal.

O caminho percorrido foi sinteticamente descrito pelo Autor em 1997, por ocasião do VI Congreso de Estudios Medievales, realizado em Léon pela Fundação Sanchéz Albornoz. Aí se podia ler o seguinte:

Quando em 1980 publiquei uma colectânea de trabalhos sobre a nobreza medieval portuguesa, antecedida de uma breve visão de conjunto dos principais problemas que a sua análise suscitava, parecia-me, e creio que estava, de facto, diante de um "campo praticammente virgem», como nessa altura dizia. Agora, passados dezassete anos, julgo que se tornou um dos mais pujantes e mais bem explorados sectores da historiografia portuguesa actual. Este facto, para o qual, sem imodéstia, creio ter contribuído com alguma coisa, deve-se, antes de mais, ao facto de que as fontes portuguesas de que os investigadores dispõem constituem um conjunto verdadeiramente privilegiado, e talvez único no mundo ocidental. Resulta, em segundo lugar, de este verdadeiro arsenal de informações ter sido interrogado de maneira sistemática e segundo uma problemática correcta e adequada, isto é, segundo os princípios da crítica documental e textual e a partir de um quadro conceptual inspirado nas ciências sociais, particularmente a sociologia dos grupos humanos, a estrutura do parentesco, a teoria das mutações sociais e a antropologia' ${ }^{11}$.

De facto, não sendo a nobreza medieva um tema propriamente original, eram-no, sem dúvida, a forma, o método e a problemática com que tinha passado a ser estudada pelos medievalistas portugueses. Em termos europeus, as genealogias medievais são geralmente textos curtos, secos e de carácter estereotipado, constituindo por isso o que é muitas vezes considerado como um género menor ${ }^{12}$. Sucede, no entanto, que as genealogias elaboradas na Idade Média portuguesa constituem, como dissemos, um caso singular em toda a Europa. Não só se revestem de uma grande e muito diversificada riqueza de informação, como têm ainda a particularidade de pretenderem cobrir toda a nobreza de Portugal, desde os tempos anteriores à fundação do reino até ao momento em que foram escritas ${ }^{13}$. O lugar central dos três nobiliários e a riqueza e variedade das suas informações para a renovação dos estudos acerca da aristocracia e das

11 «A Nobreza Medieval Portuguesa (séculos X a XIV)», in La nobleza peninsular en la Edad Media, Ávila, Fundación Sanchéz Albornoz, 1999, pp. 9-32, publicado também em Obras Completas, 1. Naquele Tempo. Ensaios de História Medieval, Lisboa, Círculo de Leitores, 2000, pp. 295-318 (a citação é retirada da página 11 e 295, respectivamente).

12 Sobre as genealogias medievais europeias como fontes históricas, veja-se GÉNICOT, L.: Les Généalogies, $\mathrm{n}^{\circ} 15$ de Typologie des sources du Moyen Age Occidental, 2a ed., Turnhout, Brepols, 1998.

13 Vejam-se os estudos de Mattoso, J.: «Os Livros de Linhagens Portugueses e a Literatura Genealógica Europeia da Idade Média», in Obras Completas, 7, A Nobreza Medieval Portuguesa. A Família e o Poder, Lisboa, Círculo de Leitores, 2001, pp. 27-41 e «A Literatura Genealógica e a Cultura da Nobreza em Portugal (séculos XIII-XIV)», in Obras Completas 8, Portugal Medieval. Novas Interpretaçoes, Lisboa, Círculo de Leitores, 2002, pp. 229-242. 
famílias da nobreza medievais justificam que nos detenhamos um pouco mais sobre eles. O primeiro, o chamado Livros Velho, foi escrito aproximadamente entre 1286 e 1290, apenas tendo chegado até nós uma pequena parte — cerca de um terço- do que teria sido a sua versão original completa. Redigido provavelmente no mosteiro de Santo Tirso, uma das mais importantes abadias beneditinas relacionadas com a alta nobreza do Noroeste de Portugal, o Livro Velho surge numa conjuntura de forte ofensiva anti-senhorial do rei Dinis, ofensiva essa que suscitou vivas reacções e veementes protestos por parte da nobreza. Neste quadro, a elaboração do Livro pretendia demonstrar as relações de parentesco que uniam aquelas que eram apresentadas como as linhagens da grande nobreza de Portugal (Sousas, Braganções, os da Maia, os de Baião e os de Riba Douro), indicadas no respectivo Prólogo como as principais responsáveis pela conquista do reino. Ao sublinhar o papel fundador da nobreza e os laços de solidariedade familiar entre os seus membros, apoiava-se e incentivavase a oposição às iniciativas anti-senhorias da Coroa $^{14}$. Quanto ao Livro do Deão, foi concluído em 1343, e inclui também um Prólogo em que são explicados os objectivos do autor, entre os quais ressaltam propósitos claramente genealógicos e simbólicos, como seja o de assinalar as mais prestigiadas linhagens, para conhecimento de reis e demais poderosos. Por outro lado, aí se diz também que a informação acerca dos laços familiares existentes entre os membros da nobreza era fundamental para que estes pudessem casar entre si sem infringirem os interditos estabelecidos pela Igreja que, como se sabe, proibia o matrimónio até ao quarto grau de parentesco do Direito Canónico. Finalmente, as linhagens nobres deveriam saber quais as igrejas e mosteiros a que se encontravam ligadas para poderem reclamar os direitos e as terras que lhes pertenciam. Ao fazer remontar as origens da nobreza de Portugal a personagens que tinham vivido no reinado de Afonso VI de Leão e Castela (1071-1109) sublinhava-se, desta forma, a anterioridade daquela e, portanto, a sua primazia face à própria Coroa portuguesa ${ }^{15}$. Por último, o Livro de Linhagens do Conde D. Pedro é assim designado por o seu autor ser Pedro Afonso, terceiro conde de Barcelos, um filho bastardo do rei Dinis, figura de grande destaque da cultura erudita do seu tempo, pois foi também autor da Crónica Geral de Espanba de 1344 e ainda poeta e compilador de poesias trovadorescas ${ }^{16}$. Escrito entre 1340 e 1344 , este Livro de Linhagens apresenta muitas semelhanças de conteúdo e de estrutura

14 Sobre a conjuntura de elaboração do Livro Velho, veja-se Krus, L., A Concepçãa Nobiliárquica..., principalmente pp. 57-70.

15 Ibidem, pp. 71-85.

16 Sobre D. Pedro, conde de Barcelos, veja-se. CinTRA, L. F. L.: na «Introdução» à sua edição crítica da Crónica Geral de Espanba de 1344, I, Lisboa, Imprensa Nacional, Casa da Moeda, 1983 (ed, facsimilada da primeira edição de 1951), sobretudo pp. CXXVII-CXC, CATALÁn MenENDEZ PIDAL, D.: De Alfonso X al Conde de Barcelos. Cuatro estúdios sobre el nacimiento de la historiografia romance en Castilla y Portugal, Madrid, Gredos, 1962 e FernANDES, A. de A.: Homenagem de Lalim ao Conde Dom Pedro. A História de Lalim, Lamego, 1990, pp. 251-313. 
com o Livro do Deão, podendo mesmo ser uma versão mais desenvolvida deste último. No entanto, o nobiliário do conde Pedro Afonso distingue-se dos dois anteriores por não se limitar à nobreza portuguesa, pretendendo abarcar, como o seu Prólogo refere, os «nobres fidalgos de Espanha» ${ }^{17}$. É assim que, além das referências a monarcas dos vários reinos da Península Ibérica, surgem igualmente famílias de Castela, de Leão e da Galiza, numa perspectiva que aponta para uma concepção unitária da nobreza hispânica, como bem demonstrou Luís Krus $^{18}$. Os objectivos de carácter genealógico e de clara valorização das famílias nobres são afirmados de modo inequívoco no Prólogo do Livro do conde de Barcelos: ao propósito geral e várias vezes manifestado de reforçar os laços de solidariedade («amor e amizade«, como se escreve ${ }^{19}$ ) entre a nobreza da Espanha, segue-se um conjunto de razões que vão desde a necessidade de os membros da aristocracia conhecerem os nomes e as acções dignas de registo dos seus ascendentes e colaterais, até à reafirmação do desejo de «saberem como podem casar sem pecado segundo os sacramentos da Santa Egreja», passando pela inevitável vontade de revelar aos reis os actos heróicos cometidos pelos antepassados da nobreza na reconquista cristã da Península Ibérica ${ }^{20}$. O autor terminava o Prólogo apelando para que a sua obra fosse continuada ao longo dos tempos, acrescentando-se-lhe as actualizações necessárias. Este apelo, que exprimia a consciência não apenas da continuidade mas também da perenidade da nobreza, encontraria resposta ainda durante o século XIV. Já depois da morte do conde Pedro Afonso de Barcelos, ocorrida em 1354, tiveram lugar duas refundições do Livro de Linhagens, em 1360-1365 e em 1380, que, em alguns pontos, não se limitaram a actualizar a matéria genealógica e introduziram alterações de forma ou de conteúdo mais ou menos significativas ${ }^{21}$. Estes nobiliários constituem não só extensos registos de indivíduos, mas também de histórias e tradições familiares. Independentemente do carácter real ou imaginário das genealogias e dos relatos que fixam no seu texto, os livros de linhagens são a expressão concentrada da imagem e da memória que a nobreza senhorial construía e procurava transmitir de si própria. Daí também a importância que estas fontes tiveram, num primeiro momento, e ainda têm para a renovação dos estudos sobre a nobreza medieval portuguesa. Não se pense, no entanto, que a multiplicação dos estudos acerca da nobreza medieva, em Portugal, se ficou a dever exclusivamente à análise dos nobiliários. O grande progresso que este campo da investigação conheceu nos últimos anos baseou-se

17 Livro de Linhagens do Conde D. Pedro, edição citada na nota 1, I, p. 58.

18 KRUS, L.: A Concepção Nobiliárquica..., passim.

19 Livro de Linhagens do Conde D. Pedro, ed. citada, I, p. 58.

20 Ibidem.

21 Sobre as refundições do Livro de Linhagens, veja-se MATTOSO, J.: na «Introdução» à sua edição crítica da obra, edição citada, I, pp. 41-50, do mesmo autor, a «Introdução» às «Narrativas dos Livros de Linhagens», in Obras Completas, 5, Lisboa, Círculo de Leitores, 2001, pp. 183-187 e KRUS, L.: A Concepção Nobiliárquica..., pp. 113 e ss. 
também num expressivo alargamento das fontes utilizadas em análises sistemáticas. Além dos fundos monásticos, pródigos em documentação muito rica para o conhecimento da realidade social da nobreza, várias tipologias documentais têm vindo a ser exploradas com sucesso. Refira-se, a este propósito, a utilização de fontes tão diversas como os registos das chancelarias reais e as «actas» de cortes $^{22}$, os inquéritos régios à propriedade e ao exercício dos direitos senhorias —as Inquiriçôes realizadas nos reinados de Afonso II (1220), Afonso III (1258), Dinis $(1284,1288-1290,1201,1304,1307)$, Afonso IV $(1335,1343)^{23}$ - a poesia lírica e satírica ${ }^{24}$, os túmulos e as epígrafes ${ }^{25}$, a heráldica ${ }^{26}$, as fortificações e os paços nobres ${ }^{27} \ldots$ É, pois, num vasto conjunto de trabalhos, de temas e

22 Por iniciativa do Centro de Estudos Históricos da Universidade Nova de Lisboa, e sob a direcção de A. H. de O. MARQues, foram já publicadas as «actas « de Cortes de Afonso IV, Pedro I, Fernando I. Quanto às chancelarias régias, o mesmo Centro editou os registos referentes aos reinados de Afonso IV, Pedro I e parte dos de João. Azevedo, I. R.., Costa , A. J. da e Pereira, M. R.: publicaram os Documentos de D. Sancho I (1174-1211), Coimbra, Centro de História da Universidade, 1979; recentemente L. VenturA e A. R. de Oliveira editaram a Chancelaria de D. Afonso III. Livro I, 2 vols., Coimbra, Imprensa da Universidade, 2006. O chamado «Livro V da Chancelaria de D. Dinis» foi publicado por SÁ-NogueIRA, B.: Livro das Lezírias D'El-Rei Dom Dinis, Transcrição, Estudo Introdutório e Notas de..., Lisboa, Centro de História da Universidade de Lisboa, 2003.

23 A título de exemplo, vejam-se os trabalhos de Mattoso, J., Krus, L., e BetTencourt, O.: «As Inquirições de 1258 como fonte da história da nobreza. O julgado de Aguiar de Sousa», Revista de História Económica e Social, 9 (1982), pp. 17-74, de MatToso, J., Krus, L. E ANDrade, A., O Castelo e a Feira. A Terra de Santa Maria nos Séculos XI a XIII, Lisboa, Estampa, 1989 ou de Ventura, L, A Nobreza de Corte de Afonso III, cit. na nota 4.

24 Vejam-se, sobretudo, o estudo de Oliveira, A. R. de, citado na nota 4 e ainda, sobre a importância das cortes senhoriais para a emergência e difusão da poesia trovadoresca, do mesmo autor, O Trovador Galego-Português e o seu Mundo, Lisboa, Editorial Notícias, 2001, e de LOPES, G. V., A Sátira nos Cancioneiros Medievais Galaico-Portugueses, Lisboa, Estampa, 1994.

25 Barroca, M.: Necrópoles e Sepulturas Medievais de Entre-Douro-e-Minho. Séculos V-XV, Porto, Faculdade de Letras, dissertação de Mestrado policopiada, 1987 e, do mesmo autor, Epigrafia Medieval Portuguesa (862-1422), 3 vols. em 4 tomos, Lisboa, Fundação Calouste Gulbenkian / Fundação para a Ciência e a Tecnologia, 2000.

26 Como sínteses, embora abarquem sobretudo o período moderno, vejam-se os trabalhos do MARQuÊS De ABRANTES, Introdução ao Estudo da Heráldica, Lisboa, Instituto de Cultura e Língua Portuguesa, 1992, e de Norton, M. A.: A Heráldica em Portugal, 2 vols., Lisboa, Dislivro, 2004.

27 BArroca, M.: «Em Torno da Residência Senhorial Fortificada. Quatro Torres Medievais na Região de Amares», Revista de História, Porto, 9 (1989), pp. 9-61 e J. C. V da SILVA, Paços Medievais Portugueses, Lisboa, Instituto Português do Património Arquitectónico e Arqueológico, 1995. Sobre a actividade militar, com relevantes elementos sobre nobreza, vejam-se os estudos de MONTEIRO, J. G.: nomeadamente $A$ Guerra em Portugal nos Finais da Idade Média, Lisboa, Editorial Notícias, 1998 e Os Castelos Portugueses dos Finais da Idade Média. Presença, Perfil, Conservação, Vigilância e Comando, Lisboa, Colibri e Faculdade de Letras de Coimbra, 1999; como síntese, veja-se a Nova História Militar de Portugal, dirigida por M. T. BARATA e N. S. TeiXeIRA, com o volume 1 dirigido por J. MATtoso e dedicado à Idade Média, Lisboa, Círculo de Leitores, 2003 (vários capítulos, da autoria de Barroca, M., Duarte, L. M, e Monteiro, J. G.). 
problemáticas que se fundamenta a afirmação de José Mattoso segundo a qual este é «um dos sectores mais fecundos da historiografia portuguesa actual» ${ }^{28}$. Aliás, esta perspectiva é confirmada pelos efeitos multiplicadores que a investigação acerca da nobreza tem vindo a ter em obras de fôlego recentemente editadas. O melhor exemplo será a colecção de biografias dos reis de Portugal publicadas entre 2005 e 2007 e cujos volumes dedicados aos monarcas medievais ou são da responsabilidade de autores que se têm dedicado especificamente ao estudo da nobreza ou conferem grande espaço e importância a tal temática ${ }^{29}$.

\section{ESTRUTURA DO PARENTESCO - O MODELO DE DUBY E O «CASO» PORTUGUÉS}

Sem dúvida que, ainda a partir dos anos setenta do século passado, o estimulante contacto com a obra de Duby foi fundamental para a análise do que poderemos chamar a família nobre, a sua estrutura e a sua evolução ao longo da Idade Média. De facto, através de um conjunto dos estudos lapidares centrados na nobreza do Norte da França, Georges Duby construiu um modelo que veio a marcar profundamente a investigação sobre a história social —incluindo as vertentes cultural e das mentalidades — da nobreza medieva. Recordemos, de forma sumária e quase esquemática, alguns dos aspectos essenciais desse modelo que seriam retomados nas análises portuguesas. Segundo Duby, entre o início do século X e meados do século XI, tinha-se assistido à passagem de uma família baseada num parentesco horizontal, de estrutura cognática, sem claro predomínio de qualquer ramo sobre os colaterais, para uma outra realidade em que se tinha imposto a linhagem, uma estrutura agnática, ou se quisermos vertical, que valorizava a primogenitura e a varonia e subalternizava os filhos segundos e as filhas, afastando-os da herança familiar com vista a garantir que o respectivo património permanecesse indiviso e, portanto, concentrado nas mãos do chefe da linhagem. No caso português, os estudos de Mattoso assinalavam um idêntico processo de mutação na estrutura do parentesco da nobreza, mas sublinhavam que essa alteração tinha ocorrido mais tarde do que no Norte da França. Assim, em Portugal, este autor escrevia que a «passagem generalizada do sistema cognático para o linhagístico ou agnático se deu durante a segunda metade do século XII» ${ }^{30}$, ou

28 Mattoso, J.: «Perspectivas Actuais sobre a Nobreza Medieval Portuguesa», in Obras Completas, 1, Naquele Tempo. Ensaios de História Medieval, Lisboa, Círculo de Leitores, 2000, p. 357.

29 Trata-se da colecção sobre os reis de Portugal editada pelo Círculo de Leitores. Os livros sobre os monarcas medievais (1139-1495) são dos autores indicados entre parênteses: Afonso Henriques (Mattoso, J.), Sancho I (Branco, M., J.), Afonso II (Vilar, H. V.), Sancho II (. Fernandes, H. G), Afonso III (Ventura, L.), Dinis (Pizarro, J. A.), Afonso IV (Sousa, B. V), Pedro I (Pimenta C.), Fernando I (Gomes, R. C.), João I (Coelho, M. H. da C), Duarte (DuARte, L. M.), Afonso V (Gomes, S.) e João II (FOnSECA, L. A. da).

30 Sobre este processo, analisado por Mattoso, veja-se Identificaşão de um País, I, Oposição, publicado nas Obras Completas, 2, Lisboa, Círculo de Leitores, 2001, pp. 172-178 (a citação é retirada da página 172). 
seja cerca de um século ou de um século e meio depois do que ocorrera na França setentrional. Mas, apesar desta importante diferença na cronologia do processo de alteração da estrutura do parentesco, o sistema linhagístico acabara por se impor, com a transmissão do património da linhagem ao primogénito varão e o consequente afastamento ou exclusão dos secundogénitos e dos elementos femininos. Ora, se não restam dúvidas sobre a progressiva afirmação de um sistema linhagístico em Portugal, viria a ser possível e necessário introduzir algumas precisões relativamente à forma de que se revestiu este processo e a certas especificidades detectáveis face ao referido modelo de Duby. Um aspecto decisivo foi, a este respeito, apontado por Leontina Ventura, ao chamar a atenção para o facto de que

desde os inícios do século XII, algumas das famílias principais (Sousa, Maia, Riba Douro, Baião e Bragança) e mesmo outras conseguiram impor um nome de família quase estável, graças ao recurso à junção do topónimo do castrum ou territorium que governavam aos nomina paterna. Este nome do castrum ou da terra ligava assim todos os descendentes ao mesmo antepassado, exaltando a linhagem (...). E ligava uma função política à linhagem, forma de patrimonialização do cargo ${ }^{31}$.

Mesmo quando a estrutura linhagística, agnática e vertical, se tornara clara entre a nobreza, a transmissão sucessória dentro da linhagem apresentava uma realidade dupla. Por um lado, as tenências das terras (circunscrições administrativas e militares) de que dispunham os ricos-homens eram muito frequentemente transmitidas de pais para filhos, segundo uma fórmula que valorizava o primogénito varão e conferia à tenência assim transmitida e ao poder político que tal cargo corporizava um carácter praticamente hereditário; o mesmo se poderia dizer, aliás, dos mais importantes cargos da cúria régia, como eram os de alferes-mor e de mordomo-mor, em torno dos quais se constituíram autênticas dinastias nobres. Mas, por outro lado, na transmissão do património familiar, até bem entrado o século XIV, manter-se-ia um sistema de partilhas igualitárias, em que todos os herdeiros se encontravam no mesmo plano e, portanto, sem qualquer privilégio para o primogénito varão e sem excluir da herança familiar nem os filhos segundos masculinos nem as filhas. Todos eles participavam, pois, na divisão igualitária dos bens da família, sem que se consiga detectar qualquer variação desta regra em função do nível ocupado pelas linhagens na hierarquia nobiliárquica. Ou seja, o processo seria idêntico quer entre a nobreza de corte, quer entre a nobreza regional, aos seus vários níveis. José Augusto de Sotto Mayor Pizarro reuniu na sua tese de doutoramento uma extensa e diversificada lista de documentos de partilhas entre membros da

31 Ventura, L.: «A Nobreza, Da Guerra à Corte», in Nova História de Portugal, dir. de J. Serrão e A. H. de O. Marques, III, Portugal em Definição de Fronteiras (1096-1325). Do Condado Portucalense à Crise do Século XIV, coord. de M. H. da C. Coelho e A. L. de C. Homem, Lisboa, Editorial Presença, 1996, p. 207. 
nobreza, abarcando a segunda metade do século XIII e indo, sensivelmente, até meados do $\mathrm{XIV}^{32}$. Da análise desse significativo conjunto de dados ressalta claramente o carácter igualitário da distribuição de bens, sem que fossem excluídos quaisquer filhos, independentemente do seu sexo (homens ou mulheres), do seu estado (solteiros, casados ou viúvos), ou até mesmo da sua condição (leigos ou clérigos). Também a diversidade de situações, relativas a partilhas entre irmãos, entre pais e filhos, entre tios e sobrinhos, aponta inequivocamente para o predomínio das partilhas igualitárias, sem que se privilegiasse o primogénito varão. A conclusão surge clara:

Face a todos estes testemunhos, tendo em conta o número, a variedade e a sua dispersão ao longo de uma cronologia bastante ampla, e atendendo também à multiplicidade de estatutos das linhagens envolvidas, somos obrigados a admitir que o regime sucessório predominante na segunda metade do século XIII e ainda durante a primeira metade da centúria seguinte, era o da divisão equitativa dos bens ${ }^{33}$.

Nesta mesma perspectiva, vale a pena atentar no caso dos Pimentéis ${ }^{34}$, pelo que ele tem de ilustrativo e mesmo de paradigmático acerca do regime sucessório aplicado nas partilhas dos bens de Vasco Martins Pimentel, que fora meirinho-mor durante parte dos reinados dos monarcas portugueses Afonso III (1248-1279) e Dinis (1279-1325). É verdade que a herança deste cavaleiro permaneceu indivisa após a sua morte, ocorrida em 1283, e que os seus filhos mantiveram durante um largo período a unidade do património paterno. Mas tal situação acabaria, no entanto, por se alterar cerca de trinta e cinco anos depois do falecimento daquele que fora o chefe da linhagem. Assim, em 1318 e, significativamente, por imposição régia, os herdeiros de Vasco Martins e de sua mulher tiveram de fazer partilhas dos referidos bens. Aldonça Vasques, monja do mosteiro de Arouca, dirigira-se ao rei Dinis por, segundo dizia, ainda não ter conseguido receber a sua parte da herança. Esta religiosa não figura nos nobiliários medievais como filha de nenhum dos dois casamentos de Vasco Martins Pimentel, mas a documentação que nos informa sobre esta ocorrência não deixa, contudo, quaisquer dúvidas acerca da sua filiação. Pela data em que tiveram lugar as partilhas Aldonça Vasques deveria, por certo, ser filha do segundo casamento de Vasco Martins Pimentel com Maria Gonçalves de Portocarreiro. Invocando a petição de Aldonça Vasques, o rei Dinis mandava citar e comparecer perante si todos os elementos envolvidos, a fim de efectuar a divisão

32 Pizarro, J. A.: Linhagens Medievais Portuguesas. Genealogias e Estratégias (1279-1325), vol. 2, Porto, Universidade Moderna, 1999, pp. 570-577.

33 Ibidem, p. 578.

34 Cf. SousA, B. V.: Os Pimentéis. Percursos de uma Linhagem da Nobreza Medieval Portuguesa (Séculos XIII-XIV), Lisboa, Imprensa Nacional, Casa da Moeda, 2000 (primeira versão datada de 1995). Este processo é pormenorizadamente analisado a páginas 255-259, onde são fornecidas todas as referências documentais. 
dos haveres e correspondente atribuição a cada um da respectiva parte. Ao todo eram referidos dezanove herdeiros, além da própria Aldonça Vasques. A identificação segura de cada uma destas personagens torna-se possível em função dos nomes e dos dados pessoais por vezes aduzidos na documentação. $\mathrm{Da}$ lista constam todos os filhos e filhas (ou os respectivos descendentes) de ambos os casamentos de Vasco Martins Pimentel, com uma única excepção, a de Aldara Vasques, nascida do segundo matrimónio de seu pai e mulher de Nuno Fernandes Cogominho, de quem não houve descendência, e possivelmente já falecida em 1318, quando ocorreu esta divisão do património familiar ${ }^{35}$. A extensa lista era encabeçada por Gonçalo Pereira, então deão do Porto, como se escreve nos instrumentos de partilhas, e futuro arcebispo de Braga. Refira-se que Gonçalo Pereira era neto de Vasco Martins Pimentel; pela mesma razão, e certamente por a sua mãe Urraca Vasques Pimentel já não ser viva, figuravam no rol os dois irmãos do citado Gonçalo Pereira mencionados no Livro de Linhagens do conde D. Pedro, ou seja Vasco Gonçalves (casado com Inês Lourenço da Cunha) e Maria Gonçalves; além destes, é bem provável que uma Teresa Gonçalves Pereira, monja de Arouca, incluída em oitavo lugar da lista, fosse também irmã dos anteriores. Em segundo lugar aparecia Martim Vasques Pimentel, cónego do Porto, filho do segundo casamento de seu pai, e em seguida vinha o Vasco Martins a quem o nobiliário do conde de Barcelos atribuía a alcunha de «o Patinho», neto e homónimo do antigo meirinho-mor do reino. Quanto a Mem Gonçalves Camelo, era marido de Inês Rodrigues Pimentel, uma outra neta do chefe da linhagem, também ela mencionada na antepenúltima posição da lista de herdeiros que temos vindo a citar. $\mathrm{O}$ irmão desta Inês Rodrigues, João Rodrigues Pimentel, figurava no sétimo lugar, e no nono estava Sancha Vasques, filha das segundas núpcias de Vasco Pimentel com Maria Gonçalves de Portocarreiro. Maria Afonso (ou Rodrigues, segundo o Livro de Linhagens), casada com Fernão Vasques Pimentel, também ele nascido do segundo casamento de seu pai, surgia em décimo lugar e o seu marido em décimo quinto. $\mathrm{Na}$ décima primeira e na décima terceira posições vinham, respectivamente, Afonso Vasques, filho do segundo matrimónio de Vasco Martins Pimentel e sua mulher, Mor Martins Zote. Entre os anteriores estava Teresa Rodrigues Bugalho, mulher de Rui Vasques Pimentel, nascido do mesmo casamento de Vasco Pimentel e por certo já então falecido. Idêntica sorte conhecera Afonso Vasques, filho do primeiro matrimónio do chefe da linhagem, pois não constava da lista, aparecendo sim os seus três filhos, Rodrigo Afonso, João Afonso e Inês Afonso, com a indicação expressa de quem era o pai. Por fim, surgia Martim Vasques de Fornelo, que identificamos como sendo o primogénito do primeiro casamento de Vasco Martins Pimentel com Maria Anes de Fornelo, aqui a usar o nome de família da mãe para não ser confundido com

35 É também possível que a referida Aldonça Vasques que requereu a partilha dos bens seja a Aldara Vasques mencionada no Livro de Linhagens do Conde D. Pedro, ed. de J. MATTOSO, 35G1, p. 400. 
o seu meio-irmão e homónimo que aparecia no segundo lugar do elenco de herdeiros. Deste vasto conjunto de nomes, e depois de haver identificado cada um dos intervenientes, o que importa sublinhar aqui é o facto de entre os herdeiros reconhecidos de Vasco Martins Pimentel se contarem todos os membros da sua vasta prole ou os respectivos descendentes, incluindo todos os secundogénitos de ambos os sexos, e sem excepção para os que haviam seguido a carreira eclesiástica ou tinham ingressado em mosteiros. A própria Aldonça Vasques, que segundo a carta régia havia tomado a iniciativa de solicitar a intervenção do rei Dinis para desencadear este processo de partilhas com vista a reivindicar a sua parte, era monja de Arouca, tal como a mencionada Teresa Gonçalves Pereira. Gonçalo Pereira, por sua vez e como se disse antes, era na altura deão da sé do Porto, e o Martim Vasques que se lhe seguia na lista era cónego da mesma cidade. Ora todos eles entraram nas partilhas e foram contemplados com uma parcela da herança. Por outro lado, a forma como se procedeu à divisão dos bens em causa e a sua distribuição pelos herdeiros são descritas em pormenor nos documentos do processo. Convocados os interessados, alguns compareceram pessoalmente ou fizeram-se representar por procuradores, outros pura e simplesmente não estiveram presentes nem representados. No entanto, as ausências não inviabilizaram o acto das partilhas, tendo os faltosos sido levados em consideração pelo meirinho régio que assim deu cumprimento ao mandado do monarca. Depois de terem sido feitos lotes dos bens, foram colocados escritos com cada um desses lotes em bolas de cera e estas bolas postas no manto de um tabelião. O mesmo meirinho começou por retirar as bolas que caberiam aos herdeiros que não tinham comparecido nem possuíam procuradores. Em seguida, cada um dos que assistiam ao acto tirou uma bola com a indicação da parcela da herança que lhe caberia em sorte. O recurso a este método do sorteio — completamente aleatório, portanto- afasta, à partida, qualquer prática de favorecimento de um dos herdeiros, sendo que, por exemplo, a quintã de Riba de Ave, uma das unidades fundamentais do património dos Pimentéis, ficou para um grupo de herdeiros que incluía Martim Vasques, cónego do Porto e de Braga, Fernão Vasques, Aldonça Vasques, monja de Arouca, e ainda Rodrigo Afonso, os seus irmãos e a mãe. A mesma Aldonça Vasques partilhava também com o seu irmão clérigo Martim Vasques uma outra quintã. Consumava-se, deste modo, a atomização da base fundiária e senhorial da linhagem. Com esta que era a terceira geração dos Pimentéis dispersava-se pelos muitos descendentes de Vasco Martins uma fortuna acumulada por este e por seu pai ao longo do século XIII. E este caso, além de não ser isolado - como o comprovam os muitos outros de natureza semelhante apontados por José Augusto Pizarro na sua tese de doutoramento- adquire ainda um significado mais profundo pelo facto de as partilhas terem sido reclamadas precisamente por uma mulher que, além de mais, era monja no mosteiro de Arouca, e que afirmava sentir-se prejudicada por a herança paterna permanecer indivisa ao fim de trinta e cinco anos após a morte do pai. As circunstâncias em que tem lugar a intervenção do rei e os procedimentos adoptados 
pelo seu meirinho apontam com clareza não para um tratamento casuístico, mas antes para uma prática estabelecida e corrente nos processos de heranças e de partilhas entre os membros de uma linhagem, em plena segunda década do século XIV. Aliás, esta não foi a primeira vez que o rei Dinis interveio directamente num processo de herança da nobreza. Embora a situação seja consideravelmente diversa da que foi estudada por Luís Krus para os bens de Gonçalo Garcia de Sousa em 1286-128736, o que é facto é que a acção do rei teve, também aqui, o nítido intuito de contrariar ou mesmo de combater a concentração de bens e de direitos senhoriais nas mãos da nobreza. A manutenção, já no decurso do século XIV, de uma prática de divisão igualitária do património entre os vários membros das linhagens nobres impediu, de facto, a constituição duradoura de vastas fortunas de base fundiária, em Portugal, inviabilizando a formação e a consolidação de grandes potentados senhoriais laicos de base regional. A aplicação de estratagemas tendentes a contrariar —ou melhor, a adiar - a inevitável tendência para a fragmentação e dispersão do património familiar, através, por exemplo, do protelamento por vários anos da realização das partilhas (como sucedeu no mencionado caso dos Pimentéis), não garantia, de modo algum, a manutenção da integridade dos bens da linhagem, mesmo que, num primeiro momento, o primogénito varão pudesse beneficiar com a indivisão. A expressa valorização do princípio da primogenitura masculina na transmissão do património nobiliárquico ganhará um estatuto institucional com o surgimento do morgadio, na viragem do século XIII para o XIV, e sua posterior difusão, à semelhança do que sucedeu noutros reinos cristãos peninsulares $^{37}$. Por meio do instituto do morgadio visava-se salvaguardar a indivisão do núcleo essencial dos bens da linhagem, transmitindo-o a um único herdeiro, o primogénito varão, ao longo das sucessivas gerações. De facto, só através do morgadio triunfará «institucionalmente» a primazia da primogenitura masculina. Em termos sociais e políticos, a fragmentação e a dispersão dos patrimónios linhagísticos ao longo dos séculos XIII e XIV —a par de múltiplas e variadas intervenções régias destinadas a conter ou, até, a pôr cobro ao exercício de certos poderes senhoriais considerados abusivos por parte da Coroa- não serão alheias ao que poderemos considerar uma fraqueza estrutural da nobreza medieval portuguesa, sobretudo se a compararmos com as suas congéneres castelhana ou francesa, por exemplo. Daí também que não se afigure adequado utilizar o termo "casa», com o sentido de uma entidade patrimonial e administrativa estável da nobreza, para a realidade portuguesa e até ao final do século XIV (com a evidente excepção dos membros da família real). Estes aspectos poderão, também, ajudar a compreender a razão pela qual não surgiram, neste período e em Portugal, poderes nobiliárquicos que disputassem de forma duradoura o poder da Coroa. A marca igualitária bem patente no regime sucessório,

36 Krus, L.: «O Rei Herdeiro dos Condes: D. Dinis e a Herança dos Sousas», in Passado, Memória e Poder na Sociedade Medieval Portuguesa. Estudos, Redondo, Patrimonia, 1994, pp. 59-99.

37 Sobre o morgadio em Portugal, veja-se a obra de RoSA, M. L., citada na nota 4. 
de que atrás se falou, não invalida que em pleno século XIII a estrutura do parentesco da nobreza em Portugal se revestisse já de uma forma inequivocamente agnática, com o predomínio da filiação unilinear masculina e a correspondente primazia das ligações verticais sobre as horizontais. Isso mesmo ressalta da organização dos próprios nobiliários medievais, com as respectivas genealogias a destacarem uma via de ascendência única, sempre que possível varonil, para estabelecer a origem dos principais grupos familiares mencionados. No entanto, e dado que o parentesco englobava quer as relações de consanguinidade quer as de afinidade (estas últimas construídas por via do casamento), os laços de solidariedade linhagística não se cingiam à cadeia estabelecida entre ascendentes e descendentes, podendo abarcar também a rede de colaterais e afins. Esta precisão é tanto mais importante quanto dela resulta que o próprio conceito de linhagem deixa de corresponder a um grupo familiar homogéneo para assumir essencialmente a expressão de um conjunto complexo e não apenas linear de relações de parentesco entre indivíduos que podem pertencer a diferentes linhas de filiação. No capítulo intitulado «Parentesco», no segundo volume da História da Vida Privada, dirigido por Duby, Dominique Barthélemy já chamava a atenção para o facto de que tanto o parentesco como a linhagem «mais do que grupos constituídos de forma rígida, designam relações» ${ }^{38}$. Daí também que, nesta perspectiva, uma mesma linhagem possa encerrar e encerre, na maioria dos casos, várias linhas verticais de gerações sucessivas descendentes de um antepassado masculino comum. Se bem que a matriz que configura a linhagem nobre seja, sem dúvida, a do parentesco vertical, isso não obriga, de modo algum, a uma concepção estreita, exclusivamente centrada numa única linha de sucessão dos grupos de parentesco nobiliárquicos, mesmo que essa linha seja considerada a principal. Nesta óptica, o conceito de linhagem contempla a inclusão no seio da mesma de eventuais ramos distintos (a partir de determinada geração), bem como a existência de linhas ou ramificações secundárias. O critério essencial para a definição da linhagem nobre será, assim, a existência de um antepassado masculino comum, ao qual remontam todas estas linhas sucessórias, antepassado esse geralmente associado ao uso e transmissão de um nome identificador, o nome de família ou apelido. Em Portugal, além da sobrevivência de elementos característicos de uma estrutura do parentesco cognática — como pudemos ver em relação ao decisivo aspecto das práticas sucessórias - jamais se teria estado, até ao final do século XIV, perante formas puras de agnatismo. De facto, a filiação materna conservou uma real importância no quadro da linhagem, em alguns casos de tal modo relevante que o nome de família seria mesmo transmitido por via feminina. No entanto, é claro que, em geral, a filiação materna se encontrava secundarizada face à paterna. Mas a transmissão do património fundiário ou mesmo do nome

38 Barthélemy, D.: «Parentesco», in História da Vida Privada, dir. por Ph. AriÈs e G. Duby, 2. Da Europa Feudal ao Renascimento, dir. por G. DubY, Porto, Afrontamento, 1990, p. 98. 
de família por via feminina, quando, por exemplo, se verificava a ausência de varonia, demonstram bem a versatilidade do sistema e a sua capacidade de adaptação para evitar, ou pelo menos retardar, a extinção da linhagem. No interior de cada linhagem concreta é possível encontrar, num mesmo momento, elementos agnáticos e cognáticos ou, se se preferir, traços de cognatismo, embora por vezes bem fortes e decisivos (como sucede com o regime sucessório aplicado ao património familiar), no seio de uma estrutura agnática dominante ${ }^{39}$.

\section{LINHAGEM E IDENTIDADE SOCIAL DA NOBREZA}

Não há dúvida de que o objectivo dos três nobiliários medievais que chegaram até nós é definir e afirmar um sentimento e uma consciência de identidade e de solidariedade da nobreza, com base no parentesco e na sua condição social. A referência comum a heróis fundadores ou a antepassados ilustres, o registo de uma história real ou fictícia, a cristalização de elementos associados a essa memória (tais como o nome de família ou a ligação privilegiada a certos lugares de culto como mosteiros e igrejas), a ideia claramente assumida da transmissão perene de um património material ou simbólico, eis alguns dos mais relevantes factores constitutivos das tradições nobiliárquicas e que ressaltam nos livros de linhagens. Sublinhe-se, a este respeito, que nos nobiliários portugueses o termo linhagem surgia tanto em sentido lato (envolvendo o conjunto dos que de alguma forma se relacionavam entre si através do parentesco), como também era empregue com o significado mais restrito de cadeia sequencial de gerações «de padre a filho», para utilizarmos a expressão usada, por exemplo, no Prólogo do Livro do conde D. Pedro. Quer nos nobiliários quer mesmo em outros tipos de fontes portuguesas dos finais do século XIII e do seguinte, não se emprega, aliás, o termo nobreza para designar o grupo social privilegiado nos campos jurídico, militar, administrativo-judicial e económico-social; quando aparece a palavra nobre não é como substantivo, mas sim como adjectivo (por exemplo: «os nobres fidalgos», para qualificar ou, se se preferir, para dar ênfase à qualidade inerente aos fidalgos). $\mathrm{O}$ vocábulo geralmente utilizado para designar o grupo aristocrático neste tipo de fontes é, de facto, fidalgos (os filbos d'algo), assim se colocando a tónica numa condição social conferida por via hereditária, pelo sangue, e não tanto pelos cargos ou pelas funções desempenhadas. Não admirará, pois, que na sua explanação dos motivos que o levaram a elaborar o Livro de Linhagens, o conde D. Pedro tenha destacado o "meter amor e amizade» — quer dizer, solidariedade_ «antre os nobres fidalgos da Espanha». Esta

39 Esta situação não parece, aliás, distinguir-se do que ocorreu na mesma época em Castela, onde a ascendência feminina e os elementos de procedência materna não foram, de modo algum, desprezados no seio da nobreza (cf. Beceiro Pita, I., y Córdoba De la Llave, R.: Parentesco, Poder y Mentalidad. La Nobleza Castellana. Siglos XII-XV, Madrid, CSIC, 1990, pp. 100-101. 
apologia da solidariedade entre os membros da nobreza era, aliás, explicada com critérios muito abrangentes, pois os fidalgos deveriam saber de quem «descenderam de padre a filho e das linhas travessas», não esquecendo, portanto, os colaterais. Dizia ainda o conde acerca do reforço dos laços de solidariedade entre os fidalgos que estes,

[...] por seerem de uum coraçom, [...], pois eles veem de uum linhagem, e sejam no quarto ou no quinto grao ou dali acima, nom devem poer deferença antre si, e mais que os que som chegados come primos e terceiros, ca mais nobre cousa é e mais santa amar o homem a seu parente alongado per dívido, se bõo é, que amar ao mais chegado, se faleçudo é. E os homees que nom som de bõo conhecer nom fazem conta do linhagem que hajam, senam d'irmãos e primos coirmãos e segundos e terceiros. E dos quartos acima nom fazem conta. Estes taes erram a Deus e a si, ca o que tem parente no quinto ou sexto grao ou dali acima, se é de gram poder deve-o servir porque vem de seu sangue. E se é igual, deve-o d'ajudar. E se é mais pequeno que si deve de lhe fazer bem, e todos devem seer de uum coraçom ${ }^{40}$.

Esta concepção alargada da solidariedade entre fidalgos, que valorizava os seus laços de parentesco, ainda que ténues, remete para a ideia de uma origem comum expressa na passagem em que se diz que «eles veem de uum linhagem», mesmo que se trate de parentes em quarto ou quinto grau, ou ainda mais afastados. Ora se nesta representação ideológica o grupo de parentesco é reconhecidamente largo, na origem do seu estatuto de distinção era apontado um elemento social — quase se poderia dizer um elemento genético- exclusivo, o sangue, transmitido de geração em geração pelos filhos d'algo. A tónica assim colocada na transmissão hereditária da condição nobre levaria a supor que estaríamos perante um grupo social muito fechado e estável, ao nível da sua composição. Mas no plano da realidade não era isso que se passava. Nos séculos XIII e XIV, pelo menos, assiste-se a uma grande mobilidade no interior da nobreza, com o declínio e a extinção de várias linhagens, com a emergência de outras e a sua ascensão na hierarquia nobiliárquica. E entre os factores que promovem essas transformações, alguns, bem importantes por sinal, escapam à lógica de uma pura transmissão hereditária. O serviço do rei, a proximidade face à corte régia, as carreiras eclesiásticas ou nas ordens militares, a ligação a grupos urbanos, as políticas de alianças associadas a estes factores, serão elementos decisivos para a renovação e para a hierarquização da nobreza. Estamos, pois, muito longe de uma nobreza estanque e fechada sobre si própria. Tal como na forma de adopção da estrutura linhagística, na transmissão do nome de família ou do património fundiário, também aqui o que sobressai não é um modelo rígido, mas sim a versatilidade e a capacidade de adaptação às situações concretas. Mesmo a instituição de morgadios, nos seus documentos fundadores, embora afirmando o princípio da primogenitura varonil para a transmissão do património, não deixava de contemplar

40 Livro de Linhagens do Conde D. Pedro, ed. de J. Mattoso, citada na nota 1, I, pp. 56-57. 
vias alternativas para as situações em que aquele preceito não pudesse ser aplicado. A adopção do sistema linhagístico, de base agnática, segundo o modelo de Georges Duby, fez integrar no meio nobiliárquico português alguns dos decisivos elementos que lhe são inerentes. Entre estes, podemos considerar a tendência para a transmissão hereditária de certos cargos políticos e administrativos de primeira grandeza, ou o surgimento de signos identitários da linhagem, como o nome de família e as armas heráldicas (que se constituem, em Portugal, a partir da segunda metade do século XII e na centúria seguinte). Mas, importa sublinhá-lo uma vez mais, nem a subalternização dos secundogénitos ou das mulheres assumiu uma expressão absoluta, nem o património material da linhagem foi transmitido hereditariamente ao primogénito varão, em exclusivo. Pelo contrário e como vimos, os filhos segundos e as filhas participaram equitativamente na partilha dos bens materiais da linhagem, já em pleno século XIV.

Os progressos verificados nos estudos sobre o tema e a abordagem sistemática das problemáticas aqui enunciadas —ou de outras que se omitiram por razões de espaço (a estratificação da nobreza, as estratégias matrimoniais e a política de alianças inter-nobiliárquicas, o papel da Coroa na hierarquização dos membros da nobreza...) _ requerem que se prossiga o caminho que vem sendo percorrido desde há, sensivelmente, três décadas. Nesta via, assumem especial importância os «estudos de caso» de linhagens específicas ou mesmo as histórias de vida de membros da nobreza que permitam detectar em que medida os modelos se adequam ou não a realidades históricas que são sempre dinâmicas, ajudando assim a compreendê-las na sua imensa complexidade. De qualquer modo, essa análise fina não deve nem pode prescindir de uma perspectiva global, entendida como a tentativa de abarcar uma visão tão completa quanto possível sobre a vida e os comportamentos dos indivíduos e dos grupos nobiliárquicos. Neste quadro de análise podem e devem convergir os aspectos das condições materiais de existência, das relações com grupos eventualmente aliados ou concorrentes, do posicionamento face às instituições políticas e aos diversos centros ou instâncias de poder. Como que envolvendo todos estes vectores, deverão também ser contempladas na análise as imagens e as representações mentais construídas acerca da realidade e da sua explicação, imagens e representações mentais essas que, não sendo directamente assimiláveis à realidade social, são, no entanto, sua parte integrante. Também as abordagens comparativas, sobretudo no quadro da Península Ibérica, poderão ajudar a esclarecer aspectos decisivos da história da nobreza medieva, com mútuas vantagens para quem as vier a empreender. Essa é, sem dúvida, uma necessidade que deriva da própria história dos reinos ibéricos, dos seus trajectos e das suas relações. E esse é, também, um desafio com o qual se confrontam, já hoje, aqueles que se dedicam ao estudo da nobreza em Espanha e em Portugal, qualquer que seja o ângulo de análise que privilegiem. Alguns passos já dados nesse sentido e os meios disponíveis para o apoio a projectos internacionais de investigação constituem, apesar das suas limitações, uma oportunidade a ter em conta e, sobretudo, a não perder. 